\section{Differentiation of Nuclear Substances}

ONE of the most used reactions of the clinicalchemical laboratory is the sedimentation reaction of the erythrocytes. It has been shown that sedimentation is hastened if, in consequence of physiopathological occurrences in the organism, the protein fractions of high molecular weight (fibrinogen, globulins) have increased ${ }^{1}$.

We were able to demonstrate by means of some typical reactions ${ }^{2}$ that the sedimentation reaction is chiefly of an unspecific nature and occurs with polysaccharides as well as with plasma proteins. We have succeeded, by fractional precipitation of the spherical colloid glycogen with methanol, in separating polymers of high molecular weight with diameters of approximately 100 glucose molecules from polymers with diameters in cross-section about ten times smaller. These different fractions of polymers produce accelerations of sedimentation which vary in accordance with their average particle size. This interdependence was shown with still greater accuracy with the rod-shaped molecules of apple pectin $^{3}$. These long, partly methylated chain molecules of galacturonic acid are easily disaggregated by neutral hydrolysis. In proportion to this hydrolysis it is possible to measure the diminution of viscosity, the scattered light (Rayleigh), as well as the effect on acceleration of sedimentation.

After these preliminary experiments the following tests were made and compared : adenylic acid from yeast (mononucleotid, mol. weight 347 ), yeast nucleic acid (tetranucleotid, $\mathrm{C}_{38} \mathrm{H}_{49} \mathrm{O}_{29} \mathrm{~N}_{15} \mathrm{P}_{4}$, mol. weight 1303 ) and thymonucleic acid kindly provided by Prof. Rud. Signer (mol. weight 600,000-1,000,000) ${ }^{4}$. The last-named substance accelerated the sedimentation of erythrocytes even in a concentration of $6 \mathrm{mgm}$. per cent in measurable extent. On the other hand, the yeast nucleic acids produced no effect even in a concentration of $400 \mathrm{mgm}$. per cent. A provisional review of these effects follows.

From fresh human blood the erythrocytes are washed three times with saline on the centrifuge, in order to attain a suspension of 100 per cent in the end. $5 \mathrm{mgm}$. of the nucleic acids are first dissolved in 0.5 c.c. of homologous serum and then diluted with 0.5 c.c. saline. Then $5 \mathrm{mgm}$. of glycogen, gelatine and pectin are first dissolved in 0.5 c.c. saline and then diluted with 0.5 c.c. serum. Now we mix carefully $0 \cdot 3$ c.c. of these solutions with $1 \cdot 2$ c.c. of the 100 per cent erythrocyte suspension. With this the concentration of the nucleic acids and the polysaccharides is brought to $100 \mathrm{mgm}$. per cent. Five minutes later the suspensions are drawn up in original Westergren pipettes, and the sedimentation read off in $\mathrm{mm}$. in corresponding periods :

\begin{tabular}{|c|c|c|c|c|c|c|c|}
\hline \multirow{2}{*}{$\begin{array}{l}\text { Additions to } \\
\text { erythrocytes }\end{array}$} & \multicolumn{6}{|c|}{ Sedimentation (min.) } & \multirow{2}{*}{$\stackrel{20}{\text { hours }}$} \\
\hline & 10 & 20 & 40 & 60 & 90 & 120 & \\
\hline $\begin{array}{l}\text { Serum and saline } \\
\text { only }\end{array}$ & - & 一 & 一 & $0 \cdot 5$ & 1 & $1 \cdot 5$ & 16 \\
\hline $\begin{array}{l}\text { Adenylic acid from } \\
\text { yeast }\end{array}$ & - & 一 & - & 0 & 1 & $1 \cdot 5$ & 16 \\
\hline $\begin{array}{l}\text { Nucleic acid from } \\
\text { yeast }\end{array}$ & - & - & & & & & \\
\hline nucleic acid & $1 \cdot 5$ & 9 & 23 & 61 & 83 & 96 & 115 \\
\hline & 二 & $\overline{-}$ & $\overline{1}$ & $\stackrel{0}{2}_{2}^{\cdot 5}$ & $\begin{array}{l}1 \\
4\end{array}$ & $\frac{1.5}{6}$ & $\begin{array}{l}18 \\
35\end{array}$ \\
\hline ctin & 2 & 26 & 89 & $11 \overline{6}$ & 119 & 120 & 123 \\
\hline
\end{tabular}

The superior effect of the high molecular threadlike molecules of the sodium salt of thymonucleic acid (desoxyribonucleic) compared with the yeast nucleic acids (ribonucleic) is -evident. Since both types of nucleic acids are polymers of mononucleotids, it follows that the new way of differentiating between them depends on their particle-size rather than on the different constitution of their ribose component. The exact interdependence of the molecular weight and the acceleration of the sedimentation of the erythrocytes could be proved with a sequence of homologous polymers like polystyrol for example. If such synthetic polymers were to be tried, one would have to ascertain that they do not possess hæmolytic properties. The substances mentioned above have none, and moreover the serum makes an excellent buffer.

University Medical Clinic,

Ch. Wunderly. Zurich. July 20.

${ }^{1}$ Gordon and Wardley, Biochem. J., 37, 393 (1943).

${ }^{2}$ Wunderly and Wuhrmann, Schweiz. med. Wchschr., 74, 185 (1944).

3 Wunderly, Viert. Jahrsschr. Naturf. Ges. Zïrich, 89, 170 (1944). Helv. chim. Acta, 26, 755 (1943).

4 Signer, Caspersson and Hammarsten, Nature, 141, 122 (1938).

\section{Influence of Blood Pressure and Blood Flow on the Activity of the Respiratory, Vasomotor and Cardio-Regulatory Centres}

The classical opinion is that changes in the central blood flow and blood pressure affect and regulate in a direct central manner the activities of the respiratory and cardio-vascular centres : decrease of central blood pressure or blood flow was considered to stimulate directly the respiratory and vasomotor centres and to inhibit directly the tone of the vagal cardioinhibitory centre; increase of central pressure or flow was considered to induce directly the opposite central reactions. Although numerous experiments performed by several different methods had shown ${ }^{1}$ that blood pressure and blood flow changes occurring in physiological and physio-pathological conditions affect the activities of the respiratory and cardiovascular centres not through a direct central action but only reflexly by way of the presso-receptor nerves of the aortic and carotid sinus areas, the classical theory of direct central regulation is still supported, particularly as regards the physiological control of the respiratory centre ${ }^{2}$. As this point is of fundamental theoretical importance, I have investigated the problem.

Experiments were performed on dogs anæsthetized with chloralosane; systemic arterial blocd pressure, heart frequency and respiratory rate, amplitude and volume were registered. The experimental results may be summarized as follows.

(a) Occlusion or desocclusion of the efferent arteries (internal and external carotid and occipital arteries) of the common carotid arteries do not affect the activity of the respiratory and cardio-vascular centres.

(b) Occlusion or desocclusion of both vertebral arteries, alone or simultaneously with the efferent arteries of the common carotid arteries, also do not affect the activity of the respiratory and cardiovascular centres, although the occlusion and release of these very important and main cerebral arteries induce very marked changes in the central blood pressure and blood supply.

(c) Decrease up to about 75 per cent of the normal blood supply or blood pressure to the isolated and perfused cerebral circulation does not stimulate directly the respiratory, vasomotor and cardioregulatory centres. 